\title{
Para além do sujeito isolado modelos antropológicos para pensar a educação
}

\author{
LÍLIAN DO VALLE \\ Universidade do Estado do Rio de \\ Janeiro, Rio de Janeiro, RJ, Brasil
}

RESUMO

Como explicar a parca atenção que a área da educação reservava e, até certo ponto, continua a reservar para a interrogação sobre o humano? Posto que a introdução da questão antropológica não implica necessariamente a volta aos engodos das verdades universais, nem se opõe, por definição, aos "recortes" a que se submete a realidade, o que se abre para nós é a via para as interrogações de que se alimenta a prática da formação e para as elucidações (provisórias e limitadas) que a teoria lhe deve. E entre elas estão, antes de quaisquer outras, aquelas que se referem aos "tipos antropológicos" da escola: o professor e o aluno. Eis o que nos conduziu à crítica da noção de interioridade e à tentativa de elucidação das bases filosóficas do duplo isolamento em que se constrói a identidade contemporânea: em relação ao outro mundo, materialidade, mas também sociedade e relações sociais - e em relação a si mesmo - heteronomia no processo de autoconstituição e de construção identitária.

\section{PALAVRAS-CHAVE}

sujeito isolado; interioridade; bases antropológicas da subjetividade contemporânea. 


\title{
BEYOND THE ISOLATED SELF: ANTHROPOLOGICAL MODELS FOR THINKING ABOUT EDUCATION
}

\begin{abstract}
How can one explain the scant attention education has devoted to the interrogation about the human being? Since the reintroduction of the anthropological issue does not necessarily imply a return of universal truths, nor precludes, by definition, the fragmentation that reality is subjected to, we aim to focus on the interrogations that feed the formative practice and on the (provisional and limited) clarifications that the theory owes it. Among them are, before any other, those that refer to the "anthropological types" of the school: the teacher and the student. This has led us to the critique of the notion of interiority and to the attempt to elucidate the philosophical bases of double isolation on which the contemporary identity is built: in relation to the other - the world, materiality, but also society and social relations -, and in relation to oneself - heteronomy in the process of self-constitution and identity construction.
\end{abstract}

\section{KEYWORDS}

isolated subject; interiority; anthropological bases of the contemporary subjectivity.

\section{MAS ALLÁ DEL SUJETO AISLADO: MODELOS ANTROPOLÓGICOS PARA PENSAR LA EDUCACIÓN}

\section{RESUMEN}

¿Cómo explicar la poca atención que el área de la educación reservaba y, hasta cierto punto, continua a reservar para la interrogación a respecto del humano? Puesto que la introducción de la cuestión antropológica no implica necesariamente el regreso a los artificios de las verdades universales, tampoco se opone, por definición, a los "recortes" a que se somete la realidad, lo que se abre para nosotros es la vía para las interrogaciones de que se alimenta la práctica de la formación y para las elucidaciones (provisorias y limitadas) que la teoría le debe. Y dentre ellas se encuentran, primeramente, aquellas que se refieren a los "tipos antropológicos" de la escuela: el maestro y el alumno. Esto es lo que nos ha llevado a la crítica de la noción de interioridad y a la tentativa de elucidación de las bases filosóficas del doble aislamiento en que se construye la identidad contemporánea: respecto al outro - mundo, materialidad, pero también sociedad y relaciones sociales - y respecto a sí mismo - heteronomía en el proceso de autoconstitución y de construcción de la identidad.

\section{PALABRAS CLAVE}

sujeto aislado; interioridad; bases antropológicas de la subjetividad contemporánea. 


\section{A ANTROPOLOGIA COMO QUESTÃO PARA A EDUCAÇÃO}

Como explicar a parca atenção que a área da educação reservava e, até certo ponto, continua a reservar para a interrogação sobre o humano? A primeira explicação que se pode oferecer é a de que esse paradoxal desinteresse - cujos reflexos sobre as formas correntes de pensar o professor, o currículo, a história das práticas formativas, as leis da educação e seu caráter instituinte, as teorias e os métodos educativos e, é claro, o aluno se deixam facilmente ponderar - decorre do prestígio de um conjunto limitado de formulações científicas (psicológicas, sociológicas, linguísticas) que, amplamente adotadas na elaboração das teorias pedagógicas, influenciaram fortemente a formação dos professores, tanto quanto a legislação e normatização das práticas escolares. Mas se, supondo as interrogações sobre o humano satisfatoriamente resolvidas por essas teorias, os educadores até hoje não se animam a questioná-las, é também, possivelmente, pela força da penetração indiscriminada da divisa segundo a qual caberia ao professor "produzir seu próprio conhecimento".

Em sua grande ambiguidade, a injunção - que a princípio parece encorajar o professor à autonomia teórica - de fato atuou, em muitos casos, de forma totalmente inversa, impedindo o professor de considerar que sua prática não é nem lugar de aplicação de um conhecimento previamente constituído, tampouco espaço de formulação de novos conhecimentos, e sim ocasião para questionamentos e deliberações que decerto servirão de base para a constituição de novos saberes, mas que permanecerão irredutíveis a qualquer tentativa de subsumi-los em uma teoria estabelecida, assim como de convertê-los inteiramente a uma nova teorização.

Não nos furtamos, porém, a atribuir parte do desinteresse da educação em relação à questão antropológica às resistências provenientes do próprio campo da filosofia, em face de uma tradição que assimilou o estudo do humano à busca de determinações universais supra-humanas e extrassociais. Não que o opróbrio que se abateu contemporaneamente sobre a "antropologia" se limite à herança metafísica: ele também foi substancialmente alimentado pelas pretensões científicas da modernidade, ${ }^{1,2}$ que apuseram ao termo a referência a uma nova disciplina que pretendia reivindicar para o estudo das manifestações humanas - representações e práticas sociais - um estatuto de rigor.

1 A modernidade buscou dar ao conhecimento do humano rigor e precisão científicos; Comte sonhava com uma "ciência positiva do espírito humano" que, para Stuart Mill, seria a psicologia. E, de fato, foi uma ambição bastante difundida na modernidade “[...] tornar o conhecimento do homem tão científico quanto o da natureza; [...] fazendo desaparecer a palavra 'filosofia', substituída pela expressão 'análise das sensações e ideias', o legislador reconheceu oficialmente que o estudo científico do espírito humano começava na França com Condillac, após a ruptura histórica que faz de Locke o pai do pensamento moderno, e que criou, por assim dizer, uma segunda Antiguidade com o século de Descartes, Malebranche, Leibniz, Spinoza” (Gouhier, 1970, p. 109).

2 Todas as traduções do francês são de responsabilidade minha. 
Entendida como ciência complementar à sociologia, a antropologia dividiu-se em duas vertentes principais: a física, exaustivamente combatida em virtude do primarismo de suas pretensões explicativas, e a social, que teve, no século passado, no estruturalismo francês talvez sua maior influência. Em todos os casos, porém, o postulado necessário de uma "ciência" antropológica é a existência de um espírito humano único, que a diversidade das formas e estilos culturais, das "mentalidades", não chega a cindir. Assim, tanto no campo da filosofia quanto no da ciência, a "antropologia" se viu diretamente associada à pretensão de erguer, contra o pano de fundo da diversidade (fenomênica, social, humana) o conjunto sólido dos universais antropológicos (Sperber, 1982, p. 18-20).

Ora, se o "humano que a cada vez a mim se apresenta" é a figura do que tenho por mais familiar, ele é também a imagem do que desconheço mais inteiramente - tanto no outro quanto, diga-se de passagem, em mim mesmo. Porque ele é o sempre diverso (Deleuze, 1978), porque ele é múltiplo, o humano resiste à unidade e, assim, à teorização. Entretanto, seria bastante leviano não acrescentar que ele resiste com igual insistência à fragmentação - à intenção de tratá-lo, por exemplo, como "mente", "motivação", "aparelho sensório-motor", "consciência"; ou mesmo como um exemplar da cultura local... Por isso, o esforço elucidativo, quando se refere ao humano, não pode jamais se aninhar no conforto das posições acabadas, mas deve enfrentar-se continuamente nos paradoxos que seu objeto impõe, pois a crítica aos excessos dogmáticos da filosofia ou da ciência não dispensa a reflexão da exigência de organizar a multiplicidade dispersa da existência em unidades de sentido, nem a dota, como por milagre, da capacidade de superar a visão parcelar, provisória e fragmentária que é a sua.

Assim, tanto quanto a introdução da questão antropológica não implica necessariamente a volta aos engodos das verdades universais, ela não se opõe, por definição, aos "recortes" a que se submete a realidade; ao contrário, na medida em que enuncia sua disposição de não reduzir o humano a eles, ela se torna sua condição de inteligibilidade. Da mesma forma, ao recusar-se a pensar o ser como noção abstrata e a priori, a questão antropológica abre a via para as interrogaçôes de que se alimenta a prática da formação e para as elucidações (sempre provisórias e limitadas) que a teoria lhe deve.

No caso da história da instituição da escola pública, parece-nos evidente que entre essas elucidações estão, em primeiro lugar, aquelas que evidenciam e submetem à crítica as representações sociais dominantes - particularmente as que se referem aos "tipos antropológicos" da escola: o professor e o aluno. Essas representações, que no Brasil do início do século XX ainda são mescladas de um tom marcadamente moralista (Do Valle, 1997a), vão aos poucos delineando a forte influência, sobre a sociedade como sobre o modelo de educação pública, do que se pode denominar de "redução cognitivista" - a desmedida valorização da cognição, em detrimento não só das demais dimensões, mas sobretudo de uma visão menos acanhada da complexidade humana. Particularmente no que se refere ao modelo original em que se apoiou entre nós a instituição da escola pública e às suas exigências mais essenciais 
(Do Valle, 1997b) - a fixação e objetivação de um projeto comum de formação básica e o amplo acompanhamento e controle desse processo -, a redução cognitiva se apresenta como uma verdadeira conditio per quam: assim, não é por acaso que a origem dessa instituição coincide com a instituição do "sujeito moderno".

É esse o contexto de construção social deste tipo antropológico próprio à modernidade, que passamos a denominar de "sujeito isolado" e que nasce da confluência de condições de organização social e econômica que impõem a ruptura com os padrões de sociabilidade anteriores e suas instituições de base. Mas, se é verdade que os novos modos de vida alimentam o esquecimento das dimensões coletivas da existência, também é fato que por ele são alimentados. É, pois, a constituição subjetiva como um todo - a relação desse humano consigo mesmo, com seu passado e progenitura, com seu futuro e descendência, com seu saber, seu corpo, seus impulsos, apetites, vontades e tendências - que sofre a influência desse isolamento, dessa alienação. Trata-se, como afirmou Hannah Arendt (1987, p. 67-68), da "privatização" do sujeito, de seu aprisionamento em uma subjetividade anônima, posto que irrepresentável; nela, essas duas faces aparecem como indissociáveis - a destruição do público levando ao desaparecimento das condições sociais de emergência da pluralidade sem a qual nenhuma singularidade pode se afirmar. Assim, a "privatização" é perda de si e, ao mesmo tempo, do outro: significa que os homens estão privados de ver e ouvir os outros, e também de serem vistos e ouvidos pelos outros.

Ao final do processo, assistimos à emergência de um sujeito que passa a desconhecer tanto suas determinações íntimas como o caráter coletivo, social, das forças que o atravessam. Para se acreditar independente, "individual" entre seus semelhantes, ele tem que ignorar (recalcar?) todas as evidências de sua dependência. (Kehl, 2002, p. 64)

Eis como o enfrentamento da questão antropológica nos conduz para a elucidação das bases filosóficas do duplo isolamento em que se constrói a identidade contemporânea: em relação ao outro - mundo, materialidade, mas também sociedade e relações sociais - e em relação a si mesmo - heteronomia no processo de autoconstituição e de construção identitária.

Ora, estabelecidas na modernidade, essas bases registram não só a estreita influência desse contexto de origens, mas igualmente a radical ruptura com os modelos e configurações da Antiguidade. É por isso que, no caso das construções antropológicas, ainda que evidentemente não só aí, o recurso às formulações antigas é não somente recomendável, mas indispensável para o exame das concepções que desde a modernidade vêm se impondo como parâmetros para a produção das subjetividades e das práticas sociais.

\section{A CRÍTICA DA INTERIORIDADE}

Correntes no pensamento contemporâneo, as críticas às definições antropológicas herdadas geralmente incidem sobre a oposição alma/corpo, sobre a distinção 
entre pensamento (consciência)/ação (movimento), ou mesmo sobre a clivagem eu (individuação)/outro (socialização), mas vêm, também, mais recentemente, implicando a recusa da noção de um "foro interior" onde o espírito se manifestaria em uma forma sempre estritamente individual, privada e dificilmente comunicável. No afã de superar essa tradição, não foram poucos os que pretenderam reduzir a existência individual a um simples elo por si só a-sensato de uma cadeia de acontecimentos causalmente ordenados por leis exteriores e objetivas. Mas há ainda os que se propõem a examiná-la a partir do que dela se apresenta em foro público, como manifestação sempre singular, ainda que necessariamente inserida em uma história e uma sociedade.

Assim, a metáfora da divisão entre "interioridade" e "exterioridade" - onipresente e difícil de ser desarraigada - tem sido objeto de críticas que, longe de compartilhar de certo maneirismo pós-moderno, parecem bastante oportunas e especialmente apropriadas para a reflexão educacional.

E isso por duas razões: em primeiro lugar, porque não se tratando, evidentemente, de buscar constituir uma nova e definitiva resposta para a espinhosa questão do ser, que muitos pensam poder simplesmente ignorar, essa reflexão tem o mérito de organizar diferentes contribuições filosóficas contemporâneas em um potente instrumental crítico para o questionamento das metáforas, das representações e dos conceitos de que nos servimos na prática corrente da formação para falar, para pensar e para interagir com o humano.

$\mathrm{E}$, em segundo lugar, porque a adoção dessa perspectiva parece responder bastante satisfatoriamente à suposta ausência de alternativas entre uma "objetividade" em tudo e por tudo redutora da diversidade fenomênica do humano e uma "subjetividade" que faria de qualquer tentativa de elucidação teórica e de toda busca de efetividade prática formas onerosas da ociosidade acadêmica e educativa.

\subsection{AS “FILOSOFIAS DO ESPÍRITO”: INTERIOR X EXTERIOR}

Na história do pensamento ocidental, as tentativas de definição do humano conduziram quase que invariavelmente à postulação de uma excepcionalidade raramente contestada, ${ }^{3}$ que, garantida por uma dimensão (propriedade, faculdade, substância) entre todos os viventes somente própria aos humanos, foi denominada, conforme o contexto, de psique, de anima, de espírito, de consciência, de mente, de

3 Não nos referimos, evidentemente, à iniciativa de diluir o humano na generalidade do "vivente" - empreendimento cujo interesse apenas as ambições de um cientificismo bastante rudimentar podem defender -, nem sequer de abrigar o animal no prestígio de certas representações humanas - antropomorfismo a que não hesitam em recorrer alguns militantes mais radicais da defesa dos animais... Afora, pois, o anedotário, vale a pena registrar a seriedade das contribuições que o estudo da condição animal vem trazendo para a investigação sobre o humano, já há mais de uma década. Destaquemos, em especial, os estudos de Boris Cyrulnik (1990); Elisabeth de Fontenay (1995); Gilbert Romeyer Dherbey (1997); e, muito especialmente, os de Jean-Louis Labarrière (2004). 
razão. Seria, evidentemente, muito arriscado propor para essas diferentes formulações outro denominador comum, além da postulação da diferença bastante enigmática, embora inegavelmente consistente, entre as "criaturas que têm, como se diz, um espírito e aquelas que não o têm” (Descombes, 1995, p. 10). E além, igualmente, do fato de que todas elas oscilam, de todo modo, entre uma generalidade incômoda e uma precisão bastante limitadora: pois que, a cada vez, parece que a caracterização do humano é excessiva e, ao mesmo tempo, insuficiente.

Há, não obstante, um modo moderno de abordar a questão; e ele tem sido fundamentalmente identificado ao movimento que Descartes inaugura, ao empreender a rígida demarcação entre corpo e alma que dominará longamente as "filosofias do espírito" da modernidade. Sem ignorar as múltiplas dificuldades que o termo "espírito" por si só introduz, mas também sem aceitar o sortilégio das palavras, devemos apenas reconhecer, com Vincent Descombes (1995), com Jacques Bouveresse (1987), ou com Claude Panaccio (1999), que a tão anunciada superação do "dualismo cartesiano" não se dará pela mera invocação de um "monismo" metodológico em tudo e por tudo problemático. A dificuldade é de monta: pois, se aceitar o dualismo implica enfrentar a aporia que consiste em pensar no modo de relacionamento possível entre dois princípios dados exatamente como irredutíveis um ao outro, matéria e espírito, o monismo, quanto a ele, apenas desloca o problema para o da postulação de uma determinação universal para todos os fenômenos e, acessoriamente, para sua hierarquização na ordem ontológica.

Não tendo a pretensão de tratar dessas questões que não só ultrapassam nossas competências como nos levariam demasiadamente longe de nosso interesse pela reflexão sobre a formação humana, aceitaremos, por ora, denominar de "filosofias do espírito" o conjunto de tentativas para pensar, com maior ou menor acuidade ou prudência, o humano. E buscaremos caracterizar, no panorama que essas tentativas abrem a partir da modernidade - e justamente porque a modernidade permanece como a origem da maior parte de nossas concepções e representações -, o fenômeno que até aqui denominamos a "redução cognitivista". Ora, ao permitir a retradução de querelas que compuseram esse panorama (hermenêutica contra positivismo, filosofia do sujeito contra estruturalismo, individualismo metodológico contra holismo mental), a crítica da interioridade sem dúvida contribui para nosso intento, permitindo que o exame do cognitivismo se enriqueça e se aprofunde. Nesse sentido, no entanto, a rígida oposição entre um "[...] dentro, segundo os herdeiros mentalistas de Descartes, de Locke, de Hume e de Maine de Biran [...], entre os quais se podem contar os fenomenólogos e os cognitivistas, e [um] fora, segundo as filosofias do espírito objetivo e do uso público dos signos, como sustentado, por exemplo, por Pierce e Wittgenstein" (Descombes, 1995, p. 10, grifos do original), terá para nós proveito rigorosamente metodológico: mais que uma tomada de posição, o que se espera que ela possa suscitar é, pelo contrário, a relativização de uma metáfora que, como toda metáfora, para realizar até o fim sua vocação heurística, deve em algum momento nos ensinar o desapego. 


\subsection{A REDUÇÃO COGNITIVISTA E O “MENTALISMO”}

Característica da modernidade, a redução cognitivista que vimos estudando é o resultado do longo processo de substituição das "filosofias do espírito" tradicionais, de caráter marcadamente moralista, pelo "mentalismo" - que assimila o espírito a um conjunto de processos interiores capazes de definir um sujeito, ou um cogito, e que produzem as significações que ele fornecerá para as coisas exteriores. A rigor, o mentalismo começa com Descartes, para quem a busca das determinações da vida interior configurava a investigação sobre a origem e organização das ideias, ou sobre as representações subjetivas. Mas deve-se atribuir à progenitura mais direta de Locke a tendência moderna a privilegiar o estudo do "entendimento humano", isso é, a intenção de identificar as leis de funcionamento dos "estados mentais".

Para o cognitivismo moderno, é como pura interioridade que a consciência pode se fazer presença direta e transparente do espírito a si mesmo, ${ }^{4} \mathrm{e}$ é nessa condição que ela se apresenta como fundamento para o conhecimento seguro. Logo, o fenômeno da consciência é garantido pela autonomia dos processos mentais, que a filosofia do espírito afirma, ao destacá-los do mundo exterior: "[...] a filosofia mental não concebe outra forma de assegurar a autonomia da psicologia além de lhe dar por objeto um espírito dissociado do mundo"(Descombes, 1995, p. 23 e 20).

Eis, pois, o que está implicado na metáfora da interioridade: o risco de se ver insidiosamente acentuado esse soberbo isolamento em relação ao mundo, esse descaso para com o enraizamento mundano dos fenômenos estudados, que, diga-se de passagem, ameaça não só as teorias da consciência formuladas a partir do século XVII, mas igualmente as teorias do inconsciente - na medida em que elas forçosamente operam com a noção de "fenômenos interiores". ${ }^{5}$

Isso sem mencionar que a questão de uma interioridade afastada de tudo que é exterior jamais deixa de introduzir o dilema com que já se defrontava o dualismo cartesiano, cindido entre o modelo psicológico da pessoa e o modelo físico do corpo, ou entre as operações cognitivas e a realidade física: em que bases pensar a comunicação entre as duas dimensões? Como poderia, como pretendeu Descartes, a alma agir sobre o corpo sem que seja, ela própria, materialidade? Por isso mesmo, Leibniz $(1974$, §59) afirmava não haver qualquer ação do corpo sobre a alma, nem da alma sobre o corpo, e apelava para a metafísica para explicar a sincronia entre eles. Freud também se deparou com o problema: e, até que deixasse para trás a ilusão

4 Nesse ponto, a corrente mais atual do mentalismo, que insiste em afirmar a natureza física das operações mentais, apresenta-se como uma ruptura da tradição que é também a de uma certa filosofia da consciência: seus defensores consideram que a mecânica que faz funcionar o cérebro humano se manifesta apenas de forma indireta, sem o controle ou a consciência do indivíduo. Mas não nos ocuparemos aqui desse mentalismo mais recente, já que sua influência sobre a educação é até aqui quase nula.

5 "Tudo começa evidentemente com Descartes, e Lacan não se equivocará ao afirmar que Freud é cartesiano e que o sujeito da psicanálise não é outro senão o sujeito da ciência moderna”, comenta Jean-Marie Vaysse (1999). 
de que a psicanálise "se pudesse apresentar como ciência", dedicou-se a buscar uma base material para os fenômenos psíquicos. ${ }^{6}$

Porém, indo ainda mais além, a separação - que, conforme os autores, é mais ou menos radical - entre um sentido espiritual e uma matéria a ser significada conduz inexoravelmente à entronização do indivíduo, já que ele e somente ele pode ser entendido como somatório de experiências imateriais, tão mais indescritíveis, que elas são, por definição, fonte de toda significação.

E é como essa variante da filosofia do sujeito que o mentalismo influenciará a escola moderna e as diferentes experiências educacionais de que ela se fará objeto. A dedicada atenção às operações da mente (ou do espírito, ou da inteligência) será a tônica comum entre propostas pedagógicas que, quase sempre insistindo sobre o caráter individual das "descobertas" cognitivas, de fato farão desmedido apelo à experiência sensível, mas isso somente para melhor consagrar o desenvolvimento das operaçôes mentais como fim último de toda formação.

\subsection{PRESENTE A SI, AUSENTE DO MUNDO}

Para o mentalismo moderno, a consciência define-se, antes de mais nada, como presença evidente e inquestionável do espírito a si mesmo. No entanto, diferentemente das acepções que pôde receber no passado, "consciência" não diz respeito a uma instância interna de julgamento, não guarda qualquer referência ou relação com as leis morais que organizam o mundo comum. Na modernidade, a consciência transforma-se, a partir da ruptura cartesiana, em uma potência de entendimento que é, concomitante e inseparavelmente, a muda experiência de si. A consciência torna-se, então - contra Malebranche e contra Leibniz -, fonte de um conhecimento puro e todo interior; posteriormente, o reconhecimento de si passa a implicar a análise, pelo espírito, de seu próprio funcionamento (Balibar, 2000).

Nisto consiste o cognitivismo: na crença de que, situado no "interior" do indivíduo, o espírito nada mais é do que presença que se traduz inteira e exaustivamente como conhecimento de si - conhecimento direto e intuitivo de suas representações ou operações mentais. O cognitivismo realiza, assim, uma dupla redução, drástica tanto em sua amplitude quanto em suas consequências, pois: (1) para que toda

6 Freud, lembra-nos Castoriadis (1987, p. 32), "muitas vezes manifestou sua esperança de que, um dia, ciências maiores em potência de positividade e exatidão - anatomia, fisiologia e patologia do sistema nervoso - pudessem dar a explicação do psiquismo e a terapia de sua perturbações”. Sem deixar de buscar as explicações psicológicas para os fenômenos psicológicos que constituirão a autonomia da disciplina que criou, o "maior psicólogo de todos os tempos", pouco antes de sua morte, será enfim levado a proclamar que "[...] uma relação direta entre a vida psíquica e o sistema nervoso, se existisse, só forneceria, quando muito, uma localização precisa dos processos de consciência, e não contribuiria em nada para sua compreensão". Em outras palavras, a identificação das bases físicas dos fenômenos psíquicos não é suficiente para explicá-los: volta-se, dessa maneira, à questão de como essas duas dimensões, de cuja indissociabilidade ninguém duvida, relacionam-se (idem, ibidem). O texto ao qual Castoriadis faz referência encontra-se em Freud, 1976, v. XVII. 
experiência de si, toda experiência da própria existência possa ser definida como cognição, é preciso, primeiramente, que (2) se converta o conjunto das dimensões humanas ao elemento mental:

Descartes incluía a sensação da dor no mental, justamente porque estimava que a dor era um pensamento, uma cogitatio - uma coisa, portanto, intelectual, e não uma coisa física. (Descombes, 1995, p. 189)

A experiência da dor provê um exemplo de como as sensações são subsumidas pela cognição: a sensação da dor, impressão física, é assimilada ao conhecimento da dor; e esse "conhecimento" todo interior da dor (pela conscientia) nada é senão a própria dor.

Importa-nos entender o terrível preço da consciência, ou do entendimento seguro: a presença a si implica paradoxalmente o afastamento do mundo, que o sujeito moderno reivindica em nome do conhecimento e do qual passa agora a se orgulhar. $\mathrm{Na}$ cena interior, em que existência é cognição, o espírito descobre sua "autonomia" em relação aos fenômenos, às coisas dadas; e essa "absolutização" do espírito - do cogito, da mente, da subjetividade transcendental - torna-se a própria marca do tipo de conhecimento que a modernidade instala no panteão de suas conquistas mais duradouras.

O afastamento do mundo que a conversão cartesiana inaugura não é, decerto, uma ausência, mas significa que a partir daí, na modernidade, a consciência-cognição-razão é condição e é medium da presença aos fenômenos - entre os quais há que se incluir aqueles que tocam à existência empírica do sujeito, esses mesmos que "[...] no campo do conhecimento [...] não poderia[m] ser senão fonte de perturbações e erros" (Castoriadis, 1997a, p. 138).

O mentalismo tem, no entanto, muitas dificuldades para lidar com tudo que não se deixa reduzir à cognição, ao conhecimento imediato e transparente: eis por que outra marca inegável do conhecimento que em sua égide se institui é a incapacidade de absorver os múltiplos sentidos da ação humana. O que, portanto, se inicia com a redução cartesiana é também o estranhamento em relação à ação, que já não pode ser vista senão como efeito de uma determinação mental:

[...] pensar que ando é mental, querer andar é mental, mas andar com o objetivo de chegar aonde se pretende não é mais que um efeito do mental. [...] a consciência cogitativa, [cujo conceito é introduzido por Descartes] [...] jamais pretendeu garantir o fato do passeio em si (acontecimento físico), mas somente o da apresentação ao espírito de algo que se dá como um passeio (acontecimento mental). (Descombes, 1995, p. 27-28, grifos do original)

Porém, também aqui seria imprudente confundir o estranhamento que o pensamento consagra com uma espécie de vocação do conhecimento moderno para a inatividade. O cerne dos embaraços se localiza, todavia, na fixação de um estatuto para a prática humana: pois o cognitivismo tem como pressuposto a possibilidade de 
reduzi-la a leis gerais. Ora, a ideia de que é possível explicar um ato voluntário por regras gerais, objetivas e anteriores a esse ato acabará paradoxalmente por repousar, como lembra Descombes, sobre a noção de um "sujeito desprovido de qualquer competência, de qualquer ação efetiva, de todo controle da situação" (idem, p. 173). Assim, a "explicação" substitui a noção do sujeito prático, já que o que se denomina de ação nada mais é que a implicação necessária de regularidades determinadas e determinantes.

Castoriadis analisa essa supressão da ação no Político de Platão, em que o monopólio da iniciativa é reservado ao epistemon, ao "Filósofo-Rei", único capaz de determinar as boas condutas (Castoriadis, 1997b): poder-se-ia então convir que na modernidade o conflito entre aquele-que-conhece-as-leis-e-sua-aplicação e aqueles-que-as-devem-aplicar se interioriza, mas não se extingue. A subsunção da iniciativa em regras preestabelecidas, sejam elas relativas às ideias intemporais ou à lógica das operações mentais, implica o ocultamento do sentido da prática humana. O modelo da "interioridade" é, pois, tornado visível pela determinação de regras de funcionando como uma espécie de "programação" que

[...] tal como a descreve Turing, repousa sobre a ideia de que se chega finalmente a operações que não exigem da parte do operador mais do que o gesto da execução. [...] De um lado, tudo que se referia a uma regra ou instrução foi explicitado ou exteriorizado: dir-se-á [...] que tudo foi formalizado. E já que a formalização teve lugar, não mais se pedirá ao calculador para utilizar um saber teórico, um conhecimento tácito que ele teria de outras regras ou de outros meios de determinar o que deve ser feito em tal ou qual caso. Seus recursos cognitivos já não são mais necessários. Ele só tem uma coisa a fazer: executar [o que lhe é ordenado]. (Descombes, 1995, p. 174, grifo do original)

\section{VOLTANDO PARA ALÉM DOS MODERNOS}

Sobre o sábio antigo, Bernard Groethuysen escrevia que ele jamais esquece o mundo, que ele pensa e age por referência ao cosmos, que ele faz parte do mundo, que é "cósmico". Do indivíduo grego pode-se dizer que, de forma menos refletida e teórica, também ele é espontaneamente cósmico. Cósmico não significa perdido, afogado no universo; entretanto, esse engajamento do sujeito humano no mundo implica para o indivíduo uma forma particular de relação consigo e de relação com o outro. (Vernant, 1991, p. 103)

Como, ao que parece, sempre se encontra no vasto mundo que é o nosso um lugar para tudo, não são poucos os que, na área da educação, insistem em ignorar a Antiguidade: não obstante as inconfessadas razões que possam estar na origem dessa recusa, pelo ato "consciente" responde muitas vezes a alegação de que o patrimônio dos antigos não mais concerniria à atualidade. Assim, uma significativa 
proporção das teorias educacionais contemporâneas tem por hábito fazer tudo partir da modernidade - condenando a radicalidade de seus esforços críticos aos limites de uma perspectiva dicotômica da história: ${ }^{7}$ o eu-contemporaneidade eternamente oposto ao outro-moderno. Ocorre, porém, que o que esse procedimento deixa à sombra é exatamente aquilo que, instituído pelos modernos, prolonga-se na atualidade sem que nos apercebamos; mas como ultrapassá-los, se as maneiras que inventaram "para pensar, para expressar-se, para sentir" nos colam na pele como uma segunda natureza?

Não fosse, pois, por outra razão, o recurso aos antigos serviria para que, ganhando certa distância em relação à nossa modernidade, possamos investir a reflexão sobre a formação humana da perspectiva que outros horizontes conceituais nos facultam. No caso presente, essa reflexão concerne às contribuições que a interrogação antropológica pode trazer para a prática da educação comum e para a crítica das representações de professor, de aluno e de formação com que ela correntemente opera.

Nosso alvo - nunca é demais repetir - é o sujeito isolado, ser que tem na cognição um modo específico de presença e de ação na realidade: o que teriam os gregos a nos dizer acerca desse conhecimento que obriga a um afastamento em relação ao aqui e agora?

Tal como para os modernos, para os gregos, ensina-nos Rémi Brague (1988, p.13), estar presente é requisito para o saber. Não há aí, no entanto, nenhuma ambiguidade possível: não se trata de presença a si, mas presença àquilo que se busca conhecer. Em outras palavras: na filosofia grega clássica, não há lugar para a relação privilegiada entre conhecimento e interioridade. ${ }^{8}$ Ao contrário, afirmava Aristóteles (1987, IX, 9.1169b 33-35), “[...] podemos ver [theôrein] com mais clareza aqueles que estão ao nosso lado que a nós mesmos, suas ações, mais que as nossas próprias”.

O "eu mesmo" é naturalmente míope em relação a si. Parece que há nessa constatação um sinal do caráter essencialmente público da vida grega, que faz da introspecção um difícil exercício, talvez mesmo quase perverso, a tal ponto que a revolução socrática seria um sintoma de decadência, mais do que sinal de

7 [...] e como não lembrar aqui de Platão (1975, 263d, grifo do original): "Ficou visível para mim que, colocando de lado uma parte, tu acreditavas ter deixado, para constituir o resto, um gênero único que, quanto a ele, compreenderia a totalidade do que restava; e tal como podias, chamando a isso 'bestas', aplicar essa mesma palavra à denominação de todos estes seres [...] assim talvez, seguindo teu exemplo, um outro animal suposto inteligente, como a grua [...], oporia a todo o resto dos animais, aquilo que um mesmo nome também lhe permite designar, isto é, a unidade do gênero 'grua'; em seguida, tomando-se a si mesma por objeto de veneração, não designaria todos os demais animais da mesma forma, pelo nome de 'bestas', uma vez que os houvesse reunido, inclusive aos homens, em um mesmo grupo? Esforcemo-nos, pois, em acumular precauções para evitar tudo o que pode se assemelhar a tal procedimento!".

8 Essa ideia do “conhecer por si mesmo", comenta Brague (1988, p. 13), será retomada por Husserl (Selbstgegebenheit), que dela fará o centro de seu programa de "retorno à coisa mesma”. 
florescimento. Seria o caso de considerar que Aristóteles faz referência à impossibilidade de se contemplar a própria atividade, dois atos não podendo ser simultâneos, e a contemplação de si permanecendo um privilégio divino? A coisa parece ser mais profunda. Mas é possível retirar desse texto uma lição: um theôrein, um olhar objetivante não pode ter acesso adequado ao fenômeno do "eu mesmo". (Brague, 1988, p. 142)

Poder-se-ia, portanto, e juntamente com o comentarista, inverter a posição moderna e postular que certa "presença a si”, longe de garantir um conhecimento seguro do que é exterior, tem na exteriorização sua condição de possibilidade. Essa é a característica da phronèsis, "[...] o lógos ético que, porque é exterior, nos situa” (idem, p. 163).

Seria todavia justa a objeção de que essa concepção marca, exatamente, a ruptura aristotélica para com a atitude filosófica defendida por Platão. Cabe, então, observar em primeiro lugar que, ao romper com seu mestre, Aristóteles só faz reafirmar o que já constitui de forma indelével seu pensamento: a aceitação da filiação e da constante interlocução que lhe oferece a tradição grega. $\mathrm{O}$ cuidado em examinar as posições instituídas em sua cultura sem dúvida não embaça a genialidade do filósofo, cuja concepção antropológica designa talvez uma das formulações mais originais da superação corpo/alma, interior/exterior, pensamento/ação:

[Em Aristóteles,] A alma humana [...] não é abordada como subjetividade, interioridade ou pensamento puro e abstrato. Já que ela é vida, ela é a alma de um corpo; ela é, original e ontologicamente, encarnada. A experiência da afetividade nos mostra claramente: "Parece, de fato, que as afecções da alma são dadas com um corpo”. (De Anima, 403 a 16). (Romeyer Dherbey, 1996, p. 6)

Mas, em segundo lugar - talvez porque não seja também possível excluir totalmente Platão do modo de ser grego... -, dever-se-á também ponderar que, separada tanto quanto possível da corruptibilidade mundana, a alma platônica tampouco dá acesso a uma experiência de presença a si; é mesmo o inverso que se dá e, em vez de interioridade, é a experiência do "inteiramente outro" que por meio dela se esboça:

Mesmo que, situando a alma no centro de sua concepção de identidade de cada um, [Platão] marque uma virada cujas consequências serão a termo decisivas, ele não abandona o quadro em que se inscreve a representação grega de indivíduo. Antes de qualquer coisa, porque essa alma que está em nós não traduz a singularidade de nosso ser, sua originalidade fundamental, mas ao contrário, como daimôn, ela é impessoal ou suprapessoal [...] Em seguida, como o conhecimento de si e a relação consigo mesmo não se podem estabelecer diretamente, imediatamente, eles permanecem presos nessa [exigência de] reciprocidade do ver e do ser visto, do eu e do outro [...]. (Vernant, 1991, p. 105) 
Mas não restam dúvidas de que é em Aristóteles, e não em Platão, que a crítica aos postulados da interioridade moderna e às consequências do mentalismo que ela impõe à educação encontrará inspiração, além de bom arsenal de munição. $\mathrm{E}$ isso não somente no sentido de que o humano em formação é mais que um ser a quem se pode, unicamente pelos recursos da cognição, ensinar a virtude, a afetividade, a sensibilidade, mas também no sentido de que ele é outra coisa além de um autômato cuja ação é inteiramente determinada por leis objetivas e infalíveis - sejam elas interiores ou exteriores.

Em Aristóteles (1987, 1224 a 23-25), a ação é primeiramente movimento (kinesis): mas o que distingue o movimento natural dos seres inanimados - uma pedra indo ao chão, por exemplo - da ação humana deliberada é, em seus próprios termos, a causa motora: "Entre os seres inanimados, o princípio [motor] é simples, mas entre os seres animados ele é múltiplo, pois o desejo e a razão nem sempre se harmonizam".

Mais especificamente, a Ética a Eudemo caracteriza o humano como o ser cujo comportamento não é naturalmente predeterminado, como é o caso das pedras, plantas, ou mesmo animais. Sobre ele, sem dúvida, operam as determinações físicas e fisiológicas que os modernos tanto enfatizaram: e Aristóteles não se esquece também das determinações que atuam sobre o humano pelo fato de que ele vive sua existência em uma comunidade precisa e segundo uma temporalidade especificamente humana. A comunidade institui as leis e a educação que se impõem sobre o sujeito, influenciando suas escolhas; e a repetição de ações que vêm dessas escolhas determina os hábitos que formam o caráter do sujeito. Mas parar aí seria confinar Aristóteles em um dilema que certamente não é o seu, mas da modernidade que pensa o um e o dois, que pensa o interior e o exterior, e nada a mais. Como afirma expressamente a Ética a Eudemo, o humano age diferentemente, conforme o caso. E, na Ética a Nicômaco,

Aristóteles [...] diz que a ação especificamente humana é aquela que deriva de uma escolha (1111b 4-10). A posição aristotélica pode ser mal compreendida, e ela frequentemente o é, como se Aristóteles houvesse dito que somente o fruto de uma escolha atual é uma ação humana [...] Ao contrário, está claro, e o próprio Aristóteles reconhece que em numerosos casos o homem age, no sentido pleno do termo, sem parar antes para deliberar e escolher. (Natali, 2004, p. 191)

No pensamento de Aristóteles, o humano e sua ação são pensados no modo da complexidade, no sentido a que aludíamos há pouco: resistência tanto à unificação quanto à fragmentação. Por isso mesmo, talvez não seja menos relevante, ainda que seja acessória, a intenção que nos anima, nesta etapa da pesquisa, de colocar em relevo a importância de sua obra para a reflexão educacional. Mas, como a qualidade e a amplitude dessa contribuição para a interrogação do humano e sua formação desautorizam e tornam contraproducentes quaisquer esforços para resumir o campo aberto para o pesquisador, talvez conviesse esclarecer a ênfase que se pretende fornecer, no seio da imensa obra aristotélica, não apenas aos 
escritos diretamente ligados à definição do humano e da ação que o caracteriza, ${ }^{9}$ mas também aos escritos que mais indiretamente estão ligados a essas questões. ${ }^{10}$ Essa ênfase se justifica pelo fato de que, fincando sua antropologia no solo consistente dos estudos sobre o vivente em geral, Aristóteles obriga a repensar os fundamentos sobre os quais a tradição moderna assentou a excepcionalidade humana. A condição animal é, pois, um tema que fornece acesso não somente a importantes contribuições da filosofia francesa das duas últimas décadas, mas a toda uma tradição antiga, para a qual contemporâneos de diversas escolas não cessam de apelar. Interrogar a animalidade implica, portanto, voltar ao momento de instituição das bases filosóficas sobre as quais se constrói, desde pelo menos os fisiocratas, que Platão e a modernidade retomam a tese da excepcionalidade humana. Ora, é essa decisão metodológica dominante que deve ser interrogada, de maneira a que se possa relançar a reflexão antropológica.

O homem não é nem o centro do universo, nem o centro do vivente, nem o centro de si mesmo. É pela observação de seu entorno que melhor o apreendemos. É preciso se descentrar para descobrir o que se é. Para esse trabalho humano, os animais nos são úteis: mais se descobrem os estados animais, mais se revela a condição humana. (Cyrulnik, 1990, p. 22)

Por isso mesmo, o estudo sobre a condição animal tornou-se para nós o operador para o questionamento das certezas herdadas - ao menos tal como as concebemos. Não se trata, é claro, de recusar ao humano os elementos de sua singularidade, ${ }^{11}$ mas de fazer da história dessa elaboração filosófica um terreno propício à reflexão sobre a formação humana.

Vista desde a perspectiva mais ampla do vivente, aberta por Aristóteles e mantida por aqueles que se nutrem de seu pensamento, a interioridade que os modernos sacralizaram já não pode ser afirmada como atributo humano por excelência, mas deve ser reconhecida, tal como Castoriadis não cessou de fazer, como característica geral do para-si (1978, p. 236). Mais ainda, é preciso rever os termos em que se postulou que a subjetividade ou mesmo a racionalidade poderiam bastar à definição do humano:

A interioridade não é a condição suficiente para o espírito [...] não é suficiente, pois é preciso atribuí-la a todo sistema funcional (natural ou concebido por um engenheiro). Todo sistema "racional" ou adaptativo possui um dentro e pratica, de acordo com as capacidades de que o dota seu meio interno, uma abstração

9 Como a Ética a Nicômaco, a Ética a Eudemo, a Política, De anima, entre outros.

10 História dos animais, Física, Partes dos animais, Parva naturalia, Movimento dos animais, entre outros.

11 Pois, como bem o lembra Jean-Louis Labarrière (2004, p. 4): “Se abolíssemos a crença - última instância e pura decisão de uma antropologia negativa - na existência de um [conjunto de características] próprio ao homem [...], cairíamos em alguma coisa ainda mais tosca que o cientificismo". 
de seu meio exterior. A divisão de interior e exterior é a de duas espécies de modificações: as que impõem ao sistema uma adaptação, e aquelas por meio das quais essa adaptação é realizada. Dir-se-á que a interioridade psicológica de que nos falam as filosofias reflexivas [...] é a que introduz a dimensão do eu. $\mathrm{O}$ interior é percebido como o próprio ou o $\mathrm{eu}$, e o exterior como o estrangeiro ou o outro. A interioridade psicológica deveria ser, assim, concebida como uma subjetividade. No entanto, a subjetividade também não é suficiente, na medida em que se entende como subjetividade o para-si [...] um tal eu não define absolutamente o espírito, pois todo sistema vivo é subjetivo ou egoísta: sua interioridade o dota de uma função de seleção do que lhe importa, a ele, e não a seu vizinho. (Descombes, 1995, p. 217-218, grifos do original)

Assim, a subjetividade é uma característica geral do para-si, de todo ser vivo, para quem existir é necessariamente manter um mundo próprio, animado por finalidades singulares. Antes de ser reservada ao humano, esse tipo de subjetividade - que se caracteriza pelo que Castoriadis (1997) denominava o fechamento cognitivo, a reclusão em um mundo próprio, pela manutenção de finalidades que se esgotam na funcionalidade (conservação/reprodução) e de um comportamento "racional" (adequação dos meios a esses fins) - descreve o modo de ser do autômato, do vivente em geral.

Aristóteles caracterizava o vivente pela conservação (1988, 415b 13), mas jamais pensou em fazer disso, como a modernidade, uma especialidade humana:

A racionalidade na execução de uma operação e, em particular, o poder do cálculo, que é um caso particular da capacidade de operar racionalmente, não são bastantes para constituir a mentalidade, para fornecer a um operador um espírito. (Descombes, 1995, p. 220)

Por isso mesmo, Castoriadis distinguia o humano pela possibilidade de romper com o comportamento inteiramente determinado pela racionalidade funcional e de, questionando os sentidos e objetivos instituídos, criar suas próprias finalidades; nisso consistia, em sua definição, a autonomia - essa outra forma de excepcionalidade que resta ainda a elucidar.

\section{REFERÊNCIAS}

Arendt, Hannah. A condição bumana. Rio de Janeiro: Forense Universitária, 1987.

Aristoteles. Catégories. Tradução de Richard Bodeüs. Paris: Belles Lettres, 2002.(9 a 1). . De anima. Tradução de Richard Bodeüs. Paris: Flammarion, 1993.

. De anima. Tradução de Jean Tricot. Paris: Vrin, 1988.

. Éthique à Eudème. Tradução de Vianney Décarie. Paris: Vrin, 1987.

.Éthique à Nicomaque. Tradução de Richard Bodeüs. Paris: Flammarion, 2004. 
Physique. Tradução de Henri Carteron. Paris: Belles Lettres, 1990.

Physique. Tradução de L. Couloubaritsis. Paris: Vrin, 1991.

Métaphysique. Tradução de Jean Tricot. Paris: Vrin, 2000.

. Mouvement des animaux. Tradução de Pierre Louis. Paris: Belles Lettres, 2002.

Politique. Tradução de Jean Aubonnet. Paris: Vrin, 1996.

Balibar, Étienne. Identidade e diferença: a invenção da consciência. Paris: Seuil, 2000.

Brague, Rémi. Aristote et la question du monde. Paris: PUF, 1988.

Bouveresse, Jacques. Le mythe de l'intériorité. Expérience, signification et langage privé chez Wittgenstein. Paris: Minuit, 1987.

Castoriadis, Cornelius. Encruzilhadas do labirinto. Rio de Janeiro: Paz e Terra, 1987.

. Feito e a ser feito. In: ___ Encruzilhadas do labirinto. Rio de Janeiro: DPA, 1997a.

Sur le Politique de Platon. Paris: Seuil, $1997 \mathrm{~b}$.

Cyrulnik, Boris. Essais sur la condition animale. Paris: Gallimard, 1990.

Deleuze, Gilles. Quatre leçons sur Kant. In: Cours Vincennes: synthèse et temps. 14 mar. 1978. Disponível em: <http://www.webdeleuze.com/php/texte. php?cle=58\&groupe=Kant\&langue=1 > . Acesso em: ago. 2001 .

Descombes, Vincent. La denrée mentale. Paris: Minuit, 1995.

Do VAlle, Lílian. A escola imaginária. Rio de Janeiro: DPA, 1997a.

A escola e a nação. São Paulo: Letras \& Letras, $1997 \mathrm{~b}$.

Fontenay, Elizabeth de. Le silence des bêtes. Paris: Fayard, 1995.

Freud, Sigmund. Compêndio de psicanálise. Obras psicológicas completas. Rio de Janeiro: Imago, 1976. (Edição Standard Brasileira, v. XVII).

Gouhier, Henri. Maine de Biran par lui-même. Paris: Seuil, 1970.

Kenl, Maria Rita. Sobre ética e psicanálise. São Paulo: Cia das Letras, 2002.

Labarrière, Jean-Louis. Aristote. Langage, vie politique et mouvement des animaux. Paris: Vrin, 2004.

La condition animale. Études sur Aristote et les stoïciens. Louvain-la-Neuve:

Ed. Peeters, 2005.

Leibniz, Gottfried. Principes de la nature et de la grâce fondés en raison. Paris: PUF, 1974.

Natali, Carlo. L'action efficace. Études de la philosophie de l'action d'Aristote. Louvain: Éd. Peeters, 2004.

Panaccio, Claude. Le discours intérieur. De Platon à Guillaume d'Ockham. Paris: Seuil, 1999.

Platão. Politique. Tradução de Auguste Diès. Paris: Belles Lettres, 1975.

Romeyer Dherbey, Gilbert. Corps et âme - sur le De anima d'Aristote. Paris: Vrin, 1996. . L'animal dans l'Antiquité. Paris: Vrin, 1997. 
Sperber, Dan. Le savoir des anthropologues. Paris: Herman, 1982.

VAysse, Jean-Marie. L'inconscient des modernes. Essai sur l'origine métaphysique de la psychanalyse. Paris: Gallimard, 1999.

Vernant, Jean-Pierre. Façons grecques d'être soi. In: Cassin, Barbara. Les grecs, les romains et nous. Paris: Éditions Le Monde, 1991.

\section{SOBRE A AUTORA}

Lílian do VAlLE é doutora em educação pela Université René Descartes, Paris 5 (França). Professora titular da Universidade do Estado do Rio de Janeiro (UERJ).

E-mail:1valle@pq.cnpq.br

Recebido em setembro de 2011

Aprovado em fevereiro de 2012 